\title{
Relationship between chemistry of air, fresh snow and firn cores for aerosol species in coastal Antarctica
}

\author{
E. W. Wolff, J. S. Hall, R. Mulvaney, and E. C. Pasteur \\ British Antarctic Survey, Natural Environment Research Council, Cambridge, England \\ D. Wagenbach \\ Institut für Umweltphysik, University of Heidelberg, Germany \\ M. Legrand \\ Laboratoire de Glaciologie et Géophysique de l'Environnement, St Martin d'Hères, France
}

\begin{abstract}
Aerosol and fresh snow concentrations have been determined at three coastal Antarctic stations, Dumont d'Urville, Halley, and Neumayer. Model estimates suggest that dry deposition, including that caused by wind pumping, is only a minor contributor (of order $1 \%$ ) to chemical fluxes at these sites with relatively high snow accumulation. Larger dry deposition fluxes are possible for very large aerosol particles, including sea-salt aerosol. Measurements of surface snow on successive days provide experimental data that constrain the contribution of dry deposition to probably less than $10 \%$ of annual fluxes for all ions, although very high episodic fluxes of giant sea-salt aerosol cannot be ruled out. Spatial variability, and frequent snow, fog and drift events, make it difficult to improve this quantification. Both theory and measurement suggest that fog deposition is also a minor contributor to the annual flux (probably $<1 \%$ ). Sublimation of surface snow and of blowing snow may increase snow concentrations by a few percent, with a larger role in summer, but should not affect fluxes. Wet deposition in falling snow appears to be by far the major contributor. However, the relationship between concentrations in snow and in simultaneously sampled aerosol at ground level was poor for most species. Scavenging ratios derived from these data are higher than those from the limited data previously available, but have huge uncertainties associated with them. Particularly at sites with frequent drifting snow, groundlevel aerosol measurements may be inappropriate for deriving scavenging ratios. Despite this, there is a general seasonal coincidence of high aerosol concentrations and high snow concentrations. We are also able to trace the chemistry of fresh snowfall to an ice core collected up to 2 years later. Although some major snowfall events may be missing, it seems that, as expected, there is no significant postdepositional modification of chemistry for aerosol species in the top meter of firn.
\end{abstract}

\section{Introduction}

For scientists studying past climate, ice cores from polar regions offer exceptional potential for increased understanding. They have already provided detailed views of changes in climate and related changes in greenhouse gas concentrations. They also contain traces of other chemicals that should have the potential to provide information about other forcing factors for, and consequences of, climate change. For instance, different chemicals are clearly influenced by volcanic activity, sea ice location, atmospheric circulation patterns, marine biological productivity, and atmospheric oxidation capacity. However, our ability to extract this information from ice core data is severely limited by difficulties in unravelling the influence of changes in source strengths, transport efficiency, and deposition efficiency [Bales and Wolff, 1995; Wolff and Bales, 1996].

In order to remedy this problem, a number of studies have been started to investigate transport to ice core sites (for example

Copyright 1998 by the American Geophysical Union.

Paper number 97JD02613.

0148-0227/98/97JD-02613\$09.00 through back trajectory calculations [Davidson et al., 1993b; Kottmeier and Fay, this issue]) and processes of air-snow transfer. The latter have included some detailed field experiments aimed at understanding the relationship between air and snow concentrations [Jaffrezo and Davidson, 1993; Davidson et al., 1996; Dibb, 1996]. It is necessary not only to measure quantitative relationships between air and snow concentrations for current conditions, but also to gain sufficient understanding to estimate relationships for conditions that prevailed in the past. This requires data from a wide range of conditions, encompassing all seasons and many locations. Until now, only very limited studies have been carried out in Antarctica, and none of these has included the entire year.

In this paper, we compare aerosol chemical concentrations from coastal Antarctica with concentrations in fresh and aged snow in order to deduce the relationships between them and to look for any seasonal dependence of such relationships. Where the experimental data prove inadequate, we have used theoretical models to estimate the contributions of individual processes. We are able to draw conclusions about which processes are crucial in determining the concentrations found in snow and ultimately in ice cores at coastal Antarctic sites. 


\section{Experiment}

This paper draws on year-round collections of aerosol and fresh snow at three coastal Antarctic stations, Halley, Dumont d'Urville, and Neumayer. Some of the chemical data are presented and discussed in other papers in this special section [Wagenbach et al., this issue; Minikin et al., this issue]. Sample collection procedures and site information are described in more detail elsewhere [Wolff et al., this issue]. The main sample set in this paper came from Halley station. At that site, aerosol samples were collected on cellulose ester filters between February 1991 and February 1993. The aerosol data used in this paper were mainly from the Halley 4 station ( $75^{\circ} 36^{\prime} \mathrm{S}, 26^{\circ} 48^{\prime} \mathrm{W}$ ), although some data from the nearby Halley 5 station are also included. The sampling interval was generally 1 day (but was extended to 2 or more days during some periods of bad weather). Filters were extracted in Cambridge and analyzed by ion chromatography [Wolff et al., this issue].

Two types of snow collection were made at Halley. The collections took place in clean areas close to the aerosol sampling sites, and the location was moved a few tens of centimetres upwind each day to ensure a new surface was used. Whenever there was a significant accumulation of snow (as determined by measurements of a stake in the snow surface), a sequence of samples was collected that more than covered the depth of the "fresh" snow. This was achieved using a sampler that could hold up to twelve 30 $\mathrm{mL}$ bottles in an overlapping vertical sequence. After digging a small hole to expose a wall of snow, it was possible to push this sampler horizontally into the wall to collect the necessary number of samples covering the accumulation. It is very important to note that accumulations at Halley are almost always accompanied by winds that cause drifting snow. It is therefore essentially impossible to differentiate true fresh snow from older snow that has been redeposited. We have therefore not attempted to do this and will refer to these samples as "accumulated" snow. They are available from July 1990 to December 1992.

In addition to the accumulated snow samples, surface samples were collected every day (weather permitting). A sampling tool, consisting of a holder with two runners that spanned two $12 \mathrm{~mm}$ diameter bottles $(9 \mathrm{~mL})$, was used. If the runners were flat on a flat surface, the sampler would collect from depths of 0-10 mm and 3$15 \mathrm{~mm}$, respectively. Undulating surfaces will have varied these depths somewhat, but both samples will have collected approximately the upper centimeter skin [Wolff et al., this issue]. These surface samples are available from July 1990 to February 1992.

The snow samples were kept frozen until analysis in Cambridge. There they were melted, and anions were analyzed by ionchromatography, using a Dionex 2010 ion chromatograph and either an AS4A column with isocratic pump (1.8mM Na $\mathrm{maO}_{3}$ $/ 1.7 \mathrm{mM} \mathrm{NaHCO}_{3}$ eluent with a concentrator column for $\mathrm{Cl}^{-}, \mathrm{NO}_{3}^{-}$, and $\mathrm{SO}_{4}{ }^{2-}, 5 \mathrm{mM}$ sodium tetraborate eluent and $200 \mu \mathrm{L}$ sample loop for MSA) or an AS11 column with gradient pump (0.5-30 $\mathrm{mM} \mathrm{NaOH}$ eluent and $200 \mu \mathrm{L}$ loop). Although a few cations were analyzed by ion-chromatography also, most were analyzed for $\mathrm{Na}$, $\mathrm{Mg}$, and in some cases $\mathrm{K}$ by flame atomic absorption spectrophotometry. For this analysis, an aliquot was acidified to $100 \mu \mathrm{M}$ to prevent ionization interference. All analyses were carried out in a Class 100 clean room. Detection limits were estimated to be approximately $0.5 \mu \mathrm{g} \mathrm{kg}^{-1}$ for the anions and $5 \mu \mathrm{g}$ $\mathrm{kg}^{-1}$ for the cations.

The amounts of snow accumulated were measured using a single white polyethylene stake. Naturally, the amount of snow accumulated at the sampling area will have varied somewhat from the amount measured at this single stake.

Aerosol samples were also collected over several years at Neumayer and Dumont d'Urville station [Wolff et al., this issue], but fewer samples of fresh snow were taken. At Neumayer, samples of fresh snow were collected under low wind conditions to ensure that they do not include drift snow: this gave only about 12 samples per year and can be compared with the low timeresolution (up to 3 weeks) of the Neumayer aerosol samples. At Dumont d'Urville, 2-4 samples of snow were collected after each snowfall [Ducroz, 1996]. Again, it was not possible to clearly differentiate between fresh snow and drifted snow.

Finally, a $2.4 \mathrm{~m}$ firn core was collected at the Halley 5 station (in the area where the second year of surface and accumulated snow samples were collected) in February 1993, just after the sampling was completed. This core was cut at an average spacing of $1.5 \mathrm{~cm}$ and analyzed for anions, to provide a detailed coverage of approximately 2 years of snowfall.

\section{Processes of Air-Snow Transfer}

For aerosol species, the main deposition processes are considered to be dry deposition of particles directly to the snow surface, wet deposition with snow or ice crystals, and fog deposition. These mechanisms have been discussed and reviewed recently [Davidson et al., 1996] and will be described briefly here. Additional processes (such as removal and redistribution of snow by drifting, and for some species, postdepositional movement) may be important in determining the final concentration that is archived in the ice core record.

Unlike other mechanisms, dry deposition occurs continuously by sedimentation, diffusion, and impaction of particles to the snow surface. The dry deposition flux is described mathematically by

$$
F_{d}=V_{d} C_{a r}
$$

where $F_{d}$ is the deposition flux (ng $\mathrm{m}^{-2} \mathrm{~s}^{-1}$ ), $\mathrm{C}_{\mathrm{arr}}$ is the air concentration ( $\mathrm{ng} \mathrm{m}^{-3}$ ), and $\mathrm{V}_{\mathrm{d}}$ is the dry deposition velocity $\left(\mathrm{m} \mathrm{s}^{-1}\right)$. $V_{u}$ can be estimated theoretically [Ibrahim et al., 1983], but can also be estimated experimentally by capturing dry deposition onto surrogate surfaces [Bergin et al., 1995b] or by measuring concentration changes in the top layer of the snow surface during periods when there is no snowfall or drift. Our daily surface snow collections at Halley provide an opportunity to estimate dry deposition by the last of these methods, although the effect of water vapor sublimation will be indistinguishable from that of dry deposition. The theoretical treatment does not include the possible effect of wind pumping which may be particularly important in areas with sastrugi [Waddington et al., 1996]. The surface snow measurements are not designed to look at this specific process, although over the year, they should include some effect of wind pumping.

Fog is believed to be a rather efficient way of depositing chemicals onto the snow surface when it occurs. The fog flux of chemicals can be written as

$$
F_{f}=V_{s} C_{f}
$$

where $F_{f}$ is fog flux (ng m ${ }^{-2} s^{-1}$ ), $V_{s}$ is the settling velocity of fog droplets $\left(\mathrm{m} \mathrm{s}^{-1}\right)$, and $C_{\mathrm{f}}$ is the chemical concentration in the fog droplets $\left(\mathrm{ng} \mathrm{m}^{-3}\right)$ [Bergin et al., 1994]. In general, the reporting of fog events significant enough to cause deposition is unlikely to be precise in our station meteorological records. However, we can investigate significant fog events at Halley to look for changes in surface snow concentrations.

Wet deposition, in which chemicals are brought to the surface by falling snow or ice crystals, includes several processes. These have been treated theoretically by various authors [e.g., Pruppacher and Klett, 1978; Shaw, 1979; Dick, 1990]. Particles may be incorporated as nuclei in the snow crystals, may become 
attached as rime (where supercooled liquid droplets attach to snowflakes and freeze), may be scavenged by snowflakes in-cloud, or may be scavenged below cloud, during precipitation. The flux of chemicals during wet deposition can be written as

$$
\mathrm{F}_{\mathrm{w}}=\rho_{\mathrm{w}} \mathrm{PC}_{\mathrm{s}}
$$

where $F_{w}$ is the wet flux (ng m $\mathrm{m}^{-2} \mathrm{~s}^{-1}$ ), $\rho_{w}$ is the density of snow meltwater $\left(1000 \mathrm{~kg} \mathrm{~m}^{-3}\right), \mathrm{P}$ is the snow precipitation rate (m water equivalent $\mathrm{s}^{-1}$ ), and $\mathrm{C}_{\mathrm{s}}$ is the chemical concentration in snow (ng $\mathrm{kg}^{-1}$ ). $\mathrm{C}_{\mathrm{s}}$ has been related to $\mathrm{C}_{\mathrm{air}}$ empirically through a scavenging ratio, $\mathrm{W}$. The mass scavenging ratio is given by

$$
\mathrm{W}=\rho_{\mathrm{arr}} \mathrm{C}_{\mathrm{s}} / \mathrm{C}_{\mathrm{air}}
$$

where $\mathrm{W}$ is dimensionless and $\rho_{\text {arr }}$ is the density of air. W can be estimated empirically for individual snowfalls provided that fresh snow is collected soon after the event. We can make this estimate from the fresh snowfall collected at all three stations but have some problems that we cannot solve: (1) We are unable unequivocally to differentiate fresh snow from drifted snow that is redeposited. (2) Our aerosol concentrations are daily averages, which may be unrepresentative for the (generally shorter) period of snowfall. (3) $\mathrm{C}_{\mathrm{aur}}$ is undoubtedly a function of altitude. We only have aerosol measurements at the surface, and not at the cloud height, which is probably more important for wet deposition.

Drifting and blowing snow, which occur frequently in coastal Antarctic stations [König-Langlo et al., In press] can affect concentrations in three ways: (1) by scavenging particles from the lower levels of the atmosphere, (2) by sublimation of water leading to enhanced chemical concentrations, and (3) if sublimation is intense enough, rerelease of previously deposited particles is possible. These processes have recently been discussed [Pomeroy and Jones, 1996]. From the Halley surface snow and accumulated snow data, we can empirically estimate the importance of drift in deposition at this site, and we can estimate theoretically the effect of process 1 .

Finally, postdepositional movement or loss of species in the snow have been reported [Wolff, 1996], although net loss is unlikely for involatile aerosol species. Some estimate of postdepositional effects may be made by comparing accumulated and surface snow concentrations with those found in cores drilled at a later date

In the next four sections, we will assess, using experimental data as well as theoretical models, the relative importance of dry, fog,

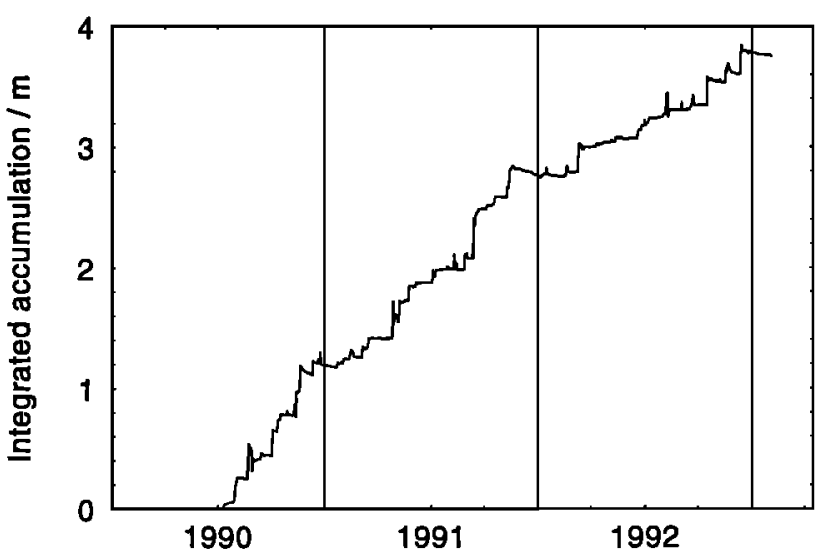

Figure 1. The integrated accumulation of snow (uncorrected for density) at Halley, based on daily measurements of a single stake. Most of the accumulations (both positive and negative) occur during drifting or blowing snow episodes.
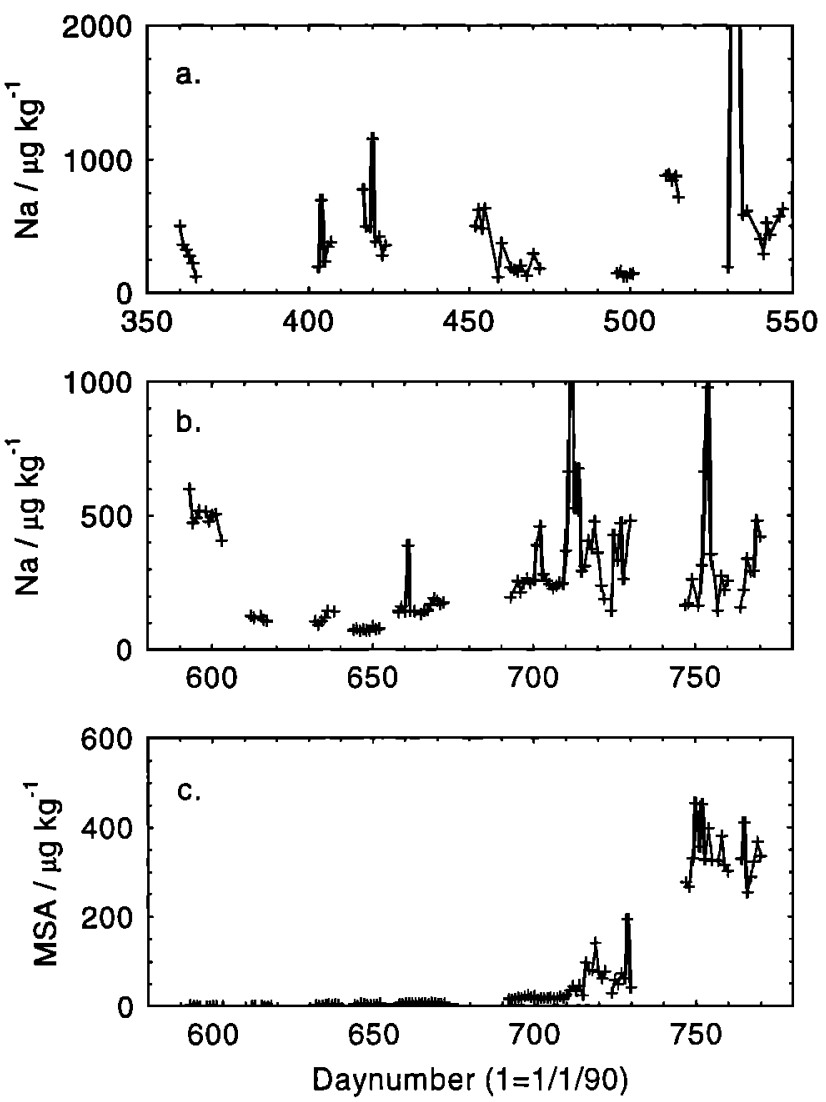

Figure 2. Concentrations of sodium and MSA in surface snow (method of collection described in text) at Halley for periods (minimum 4 days) when there was no significant snow accumulation at a nearby snow stake. The values shown are the average of two samples from the surface snow sampler each day. The day numbers refer to a scale where $1 / 1 / 90$ is day 1 . (a) $\mathrm{Na}$ from December 1990 to June 1991; (b) Na for August 1991 to February 1992; and (c) MSA for August 1991 to February 1992.

and wet deposition, as well as the effects of drifting and blowing snow, on chemical concentrations in snow. We then take a more general overview to assess the quality of translation from aerosol to ice core records.

\section{Dry Deposition}

Comparisons of chemical fluxes with snow accumulation rates have been used to suggest that dry deposition contributes the majority of chemical deposition fluxes for several chemical species at sites in central Antarctica, which have very low ( $\left.<50 \mathrm{~kg} \mathrm{~m}^{-2} \mathrm{yr}^{-1}\right)$ snow accumulation rates [Pourchet et al., 1983; Legrand, 1987]. On the other hand, field campaigns have suggested a relatively minor role for dry deposition for a range of ions during summer at Summit, Greenland [Bergin et al., 1995b], and for sulfate for the full year at Dye 3, Greenland [Davidson et al., 1993a]. These sites have larger snow accumulation rates, of about $210 \mathrm{~kg} \mathrm{~m}^{-2} \mathrm{yr}^{-1}$ for Summit and $500 \mathrm{~kg} \mathrm{~m}^{-2} \mathrm{yr}^{-1}$ for Dye 3. In this section, we estimate the importance of dry deposition at Halley, Antarctica.

\subsection{Experimental Estimates of Dry Deposition}

One way of assessing the importance of dry deposition is to examine days, or sequences of days, when no accumulations of snow occurred, and to estimate the chemical flux to the surface from the change in concentration of the surface skin. As can be seen from Figure 1, although snow accumulations occur at any time 
of year, many plateaus with minimal accumulation occur at our measuring stake at Halley.

From Figure 2, it is immediately apparent that there are problems with this approach to estimating dry deposition. The concentrations seen in surface snow can fluctuate wildly in periods when no significant snow accumulations occurred at the snow stake. The result for sodium is seen also for other ions, including methane sulfonic acid (MSA) (Figure 2c). There can be a number of reasons for these fluctuations, which are often far too large to be due to dry deposition alone.

1. Although large accumulations $(>1.5 \mathrm{~cm}$, sufficient to trigger sampling with the accumulated snow sampler) were recorded on only 35 days in 1991, small accumulations (of a few millimeters) are occasionally recorded at the snow stake in these periods. Detailed study of the 3-hourly meteorological records from Halley show that in 1991, there was at least one (from the eight observations in a 24-hour period) observation of snowfall (all but one listed as slight or moderate) on 184 days, of fog depositing rime on 41 days, and of drifting or blowing snow on 164 days. In all, one of these events was recorded on 267 of the 365 days. It is therefore improbable that one can find a sequence of days when absolutely no change to the surface could have occurred.

2. Snow accumulation can be rather patchy. This is observed particularly after snow drift events, when soft deposits of recently drifted snow alternate with hard deposits of (presumably) older snow. This has two consequences. First, it is possible for accumulation to have occurred at our sampling area on a given day, without any accumulation at the snow stake. Second, it leads to significant spatial variability. Over very short distances (of order 10 centimeters), we have assessed this variability by comparing the concentrations in the two surface samples (assuming they in fact collect from the same depth). The two concentrations are wellcorrelated with each other (correlation coefficients $>0.9$ ), with an average difference between the two values of approximately $20 \%$ for all ions. Over greater distances, larger variations (up to about $60 \%$ ) can be seen [Pasteur, 1996], probably reflecting changes between different "vintages" of accumulation. These spatial variabilities are of similar magnitude to those observed in a large survey of surface snow carried out in a $1 \mathrm{~km}^{2}$ grid at Summit, Greenland [Dibb, 1996], and to those seen in individual layers of a snow pit at Summit [Steffensen et al., 1996].

For our collections, because the sampling site moved upwind from day to day, it is likely that sometimes we moved, for example, from softer drifted snow to harder older snow and viceversa. This could lead to major changes in concentration despite no new accumulation occurring. This seems, for instance, to be a likely explanation for the huge variations occurring around day 710 : these concentrations are replicated in both surface samples, so that short distance variability cannot be the cause. Either the sampling site is moving across different surfaces, or successive accumulation events occurred, large enough to completely alter an approximately $1 \mathrm{~cm}$ thick layer.

Whichever of these is the cause, it poses a problem for the assessment of dry deposition. We attempt two experimental approaches to this problem. A first approach is to look for the brief periods when absolutely no accumulation should have occurred; that is, when there were no reports of rime depositing, of drifting or blowing snow, or of snowfall. We identified only 10 such periods in 1991, mainly of just 2 days. Although, as expected, the variability was much less in these shorter periods, it was still observed that concentrations for all ions both rose and fell in the different periods, so that no meaningful measures of dry deposition could be obtained from such a small remnant data set.

A second approach is to look in the data set for periods when there were no significant accumulations ( $<0.5 \mathrm{~cm}$ al snow stake), and the concentration changed little. If we assume that on these days we are sampling the same surface, then we can use aerosol data to derive maximum dry deposition velocities. Examples of such periods would be (Figure 2) the several day periods around day $380,460,500,515,590,610,650,670$, and 700 . To derive the maximum flux, we assume that the samples collect a $1 \mathrm{~cm}$ thick layer of snow with a density of $300 \mathrm{~kg} \mathrm{~m}^{-3}$. Then, each gram of snow represented $3.3 \mathrm{~cm}^{2}$ of the surface. In fact, the true sample depth was likely a little less, and the area a little larger, but using this value will give an upper estimate for dry deposition. Using equation (1), we can plot the daily change in concentration against the aerosol concentration for the same 24-hour period, and the gradient will be the dry deposition velocity scaled by the factor above $\left(3.3 \mathrm{~cm}^{2} \mathrm{~g}^{-1}\right)$. We were able to identify 10 suitable periods between January 1991 and February 1992, each of 4 or more days. The scatter on individual daily values is very large: for example, the values for $\mathrm{Na}$ and MSA derived from the gradients of Figure 3 are $-0.2 \pm 0.8 \mathrm{~cm} \mathrm{~s}^{-1}$ and $-0.5 \pm 0.4 \mathrm{~cm} \mathrm{~s}^{-1}$, respectively. This provides little constraint on the dry deposition velocity, but suggests that it is of order $1-2 \mathrm{~cm} \mathrm{~s}^{-1}$ or less.

It is clear that it is not possible to derive any value (other than gross upper limits) for dry deposition velocity from a site with significant spatial variability, unless the same surface is stable for very long periods. Although it suffers from the flaw that the deposition velocity could be different for different types of surface, the alternative method of collecting dry deposition on clean surrogate surfaces (such as Teflon sheets [Bergin et al., 1995b]) may be more successful in supplying a useable velocity.
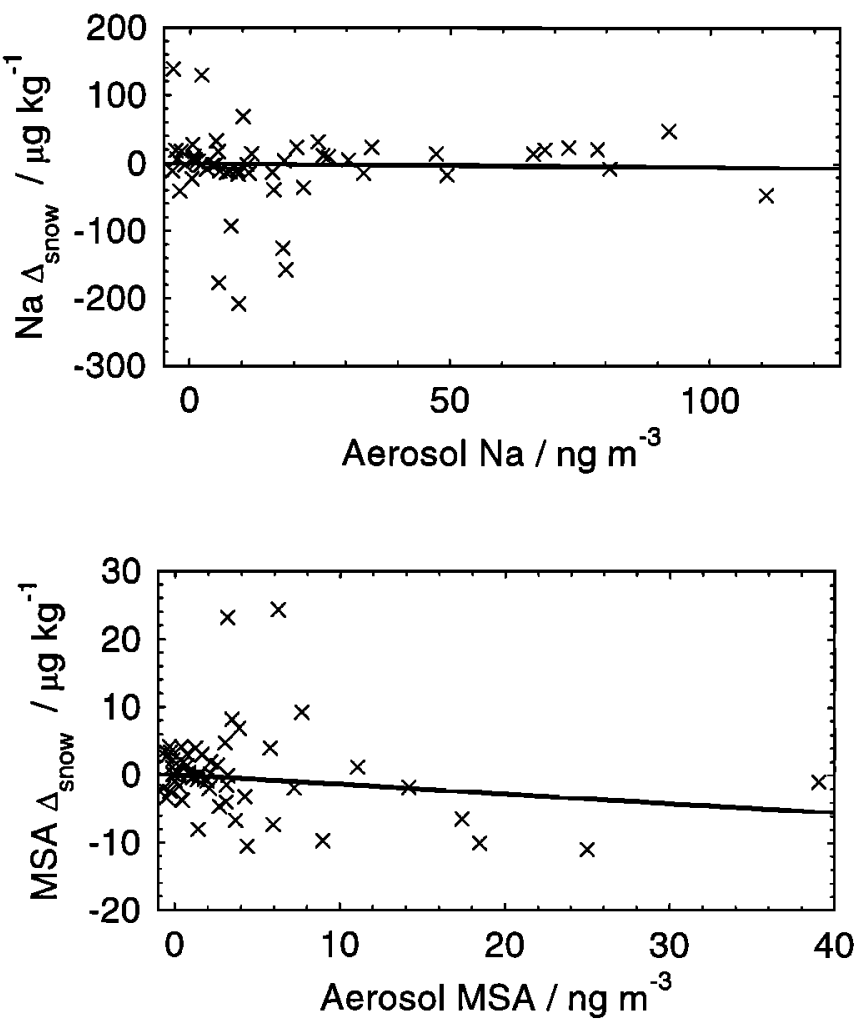

Figure 3. Scatterplot of daily changes in surface snow concentration $\left(\Delta_{\text {snow }}\right)$ against aerosol concentration at Halley for sodium and MSA, for days when there was no significant accumulation, restricted to periods of relatively stable concentrations. In each case, the line is the best fit forced to pass through zero. 


\subsection{Model Estimates of Dry Deposition}

An alternative way of approaching dry deposition velocities is through the use of models. Such models calculate the sizedependent deposition velocities for the different processes of dry deposition. Applying a simple model to dry deposition of particles in the Antarctic Peninsula, Dick [1990] derived dry deposition velocities of $0.002 \mathrm{~cm} \mathrm{~s}^{-1}$ for $0.3 \mu \mathrm{m}$ diameter particles and $0.14 \mathrm{~cm}$ $\mathrm{s}^{-1}$ for $2 \mu \mathrm{m}$ particles. A more complex model [Ibrahim et al., 1983] was applied to snow at Dye 3, Greenland [Davidson, 1989]. We can use the results derived for Dye 3, knowing that the roughness length is very similar at Halley [King et al., 1996] to that used for Dye 3, and allowing for the faster wind speeds at Halley [König-Langlo et al., this issue]. We would then estimate dry deposition velocities at Halley of order $0.001 \mathrm{~cm} \mathrm{~s}^{-1}$ at $0.3 \mu \mathrm{m}$ diameter and $0.04 \mathrm{~cm} \mathrm{~s}^{-1}$ at $2 \mu \mathrm{m}$ diameter. This model gave reasonable agreement (within a factor 2 ) with measured deposition velocities measured using a surrogate (Teflon) surface at Summit, Greenland [Bergin et al., 1995b]. The measured velocity for sulphate at Summit was $0.041 \mathrm{~cm} \mathrm{~s}^{-1}$.

Since we do not have any particle size distributions for Halley, we cannot directly use the models described. Nonetheless, we can expect that the particle sizes for MSA and non-sea-salt (nss) sulphate will be in the range $0.1-1 \mu \mathrm{m}$, while the sea-salt particles, representing a rather local source, may be as large as a few microns. The very largest sea-salt particles, which could have diameters of $10 \mu \mathrm{m}$ or more, would probably not be collected by our aerosol samplers [McDonald et al., 1982; Wagenbach et al., this issue]. An overall deposition velocity will be heavily biased toward the largest particles (because it is a mass average). On the basis of the model, we would therefore expect dry deposition velocities to be of order $0.04 \mathrm{~cm} \mathrm{~s}^{-1}$ for MSA and nss sulphate and typically of order $0.2 \mathrm{~cm} \mathrm{~s}^{-1}$ for sea-salt. However, it is possible that there are occasions when very high concentrations of very large sea-salt aerosol could be present, which would not be efficiently collected by our aerosol samplers, but which would have very high deposition velocities (a few $\mathrm{cm} \mathrm{s}^{-1}$ due to sedimentation for particles with diameter $10 \mu \mathrm{m}$ or more). Because sea-salt aerosol concentrations and flux to the snow surface are highly episodic, it is possible that this dry process is very important to the overall annual flux, although dry deposition is probably not important for most of the year. In fact, very large particles are likely to be transported in conditions of rather strong winds, when snow drift is also occurring. As a result, it is probable that scavenging by drifting snow (see section 7) is the final removal mechanism for such very large aerosol particles, although dry sedimentation is the mechanism that replenishes the near-surface layer of air.

Our surface snow measurements discussed in section 4.1 impose an experimental limit for all ions of about $1 \mathrm{~cm} \mathrm{~s}^{-1}$ in most cases, but again do not account for unmeasured very large sea-salt particles.

On the basis of the amount of, and concentrations in, accumulated snow (discussed later), we can calculate a total deposition flux at Halley for 1991 for each ion. With the average aerosol concentrations for $1991\left(9 \mathrm{ng} \mathrm{m}^{-3}\right.$ for MSA, $94 \mathrm{ng} \mathrm{m}^{-3}$ for $\mathrm{Cl}^{-}$), we can estimate the contribution of dry deposition for different deposition velocities. At $0.04 \mathrm{~cm} \mathrm{~s}^{-1}$, dry deposition could only contribute $0.4 \%$ of the total deposition of MSA in 1991, while at $0.2 \mathrm{~cm} \mathrm{~s}^{-1}$, dry deposition would contribute $1.5 \%$ of sea-salt deposition. Even at $1 \mathrm{~cm} \mathrm{~s}^{-1}$, the dry deposition contribution would be under $10 \%$. We therefore conclude that, excepting for any times when giant particles $(>10 \mu \mathrm{m})$ are present, dry deposition is a very minor contributor to the fluxes of ions (and therefore the concentrations) to snow at Halley (Table 1). However, it is possible that on an annual basis, a few extreme events of very large sea-salt aerosol do make a more significant contribution to the seasalt budget to the snow. We can do similar calculations at Neumayer (using average aerosol concentrations and an estimate of average snow concentrations) and conclude that, with our suggested aerosol particle sizes, dry deposition should only contribute less than $5 \%$ to the fluxes there (again excluding the influence of very large particles). This low contribution of dry deposition is likely to be the case for any site with snow accumulations in a similar range to those seen at Halley, that is to most of coastal Antarctica and the Antarctic Peninsula. However, measurements of the size distributions of aerosol are needed to substantiate these estimates. For coastal sites, it is clearly important to account for giant particles, which may make up a very significant proportion of mass (especially for sea-salt), although this may be less important for all noncoastal sites.

Table 1. Estimate of Contribution to Annual Flux at Halley in 1991 From Different Sources

\begin{tabular}{lrrrrr}
\hline & MSA & $\mathrm{Cl}^{-}$ & $\mathrm{SO}_{4}{ }^{2-}$ & $\mathrm{Na}$ & $\mathrm{Mg}$ \\
\hline Dry deposition (model) & 10 & $600^{*}$ & $80^{*}$ & $240^{*}$ & $19^{*}$ \\
Wind pumping (model) & $<25$ & $<300$ & $<170$ & $<120$ & $<10$ \\
$\begin{array}{l}\text { Dry deposition plus wind pumping } \\
\quad \text { plus surface sublimation } \\
\text { (observation, based on 1 } \mathrm{cm} \mathrm{s}^{-1} \text { ) }\end{array}$ & $<250$ & $<3,000$ & $<1,700$ & $<1,200$ & $<100$ \\
$\begin{array}{l}\text { Fog deposition (model) } \\
\begin{array}{l}\text { Fog deposition } \\
\text { (observation) }\end{array}\end{array}$ & 3 & 56 & 18 & 17 & 2 \\
$\begin{array}{l}\text { Scavenging by blowing snow } \\
\begin{array}{l}\text { Accumulated (or fresh) } \\
\text { snow (observation) }\end{array}\end{array}$ & 1120 & $<3,000$ & $<800$ & $<1,500$ & $<270$ \\
\hline
\end{tabular}

All values are in $\mathrm{ng} \mathrm{cm}^{-2}$. The various calculations are described in the text. Sublimation from the snow surface and from blowing snow are not included here but are discussed in the text.

*The possible effect of very large particles is not included here and could increase the dry deposition for sea-salt ions substantially (see text). 


\subsection{Wind Pumping}

Model calculations of dry deposition do not include the possible effect of windpumping through surface topography [Harder et al., 1996; Waddington et al., 1996], nor the concentrating effect of water vapor sublimation from the snow surface, although our surface snow estimates will include both these effects. We estimate their importance at Halley.

Wind pumping has been treated in some detail by Waddington [1996], who presents plots of deposition velocities due to this effect as a function of the height, wavelength, and aspect ratio of topographic features (such as sastrugi). Field measurements of the filtering efficiency of snow suggest that the $e$-folding depth is $<1 \mathrm{~cm}$, so that any wind-pumped material should be found in our surface samples. To apply the model, we need to estimate the parameters of the topographic features at Halley and also account for the effect of a different wind speed.

There has been no systematic study of the size and shape of topographic features at Halley, though they are certainly smaller than those reported from the Antarctic plateau. Our observations suggest that surfaces typically consist of a combination of larger features with heights of order $10-30 \mathrm{~cm}$ and wavelengths $2-10 \mathrm{~m}$, along with smaller features perhaps $2 \mathrm{~cm}$ high and $10 \mathrm{~cm}$ in wavelength. In both cases, the aspect ratio is considerably less than 1. The smaller features in particular tend to have icy, presumably impermeable faces that would inhibit wind pumping. The volumetric air flux (and hence the deposition velocity) is proportional to the wind speed squared, and therefore the results given by Waddington [1996] have to be scaled by the square of the rms wind speed (which at Halley is close to $8 \mathrm{~m} \mathrm{~s}^{-1}$ as compared to the mean speed of $6.2 \mathrm{~m} \mathrm{~s}^{-1}$ ).

For the size and shapes given above, the model would estimate deposition velocities of about $0.2 \mathrm{~cm} \mathrm{~s}^{-1}$ for the larger features and as high as $3 \mathrm{~cm} \mathrm{~s}^{-1}$ for the smaller features. However, the probable impermeability of the smaller features means that $0.2 \mathrm{~cm} \mathrm{~s}^{-1}$ is probably more realistic. Furthermore, the sizes quoted are typical for areas that have sastrugi. At Halley, at any given moment, only a small percentage of the surface is covered by sastrugi (and therefore at a given location, there are sastrugi for only a small proportion of the year). When no sastrugi are present, only subtle, long wavelength features (with expected deposition velocities $<0.01 \mathrm{~cm} \mathrm{~s}^{-1}$ ) are present. We therefore believe that the relevant average deposition velocity for wind pumping at Halley is probably well below $0.1 \mathrm{~cm} \mathrm{~s}^{-1}$, which is negligible compared to total deposition, and possibly even compared to "normal" dry deposition. Although wind pumping may be important at sites with lower snow accumulation rates and larger, more persistent sastrugi, it probably contributes little to the chemical fluxes at coastal sites, such as Halley.

\subsection{Sublimation From the Snow Surface}

Sublimation of water vapor from the snow surface would be seen as an increase in chemical concentrations in our surface snow records. This could be misinterpreted as dry deposition. It has no net effect on the chemical flux to the ice sheet, but does affect the concentration record. Reductions in the surface level are seen at snow stakes, due to a combination of settling of low-density snow and sublimation. At our stake at Halley, by far the greatest number of small $(<1 \mathrm{~cm})$ reductions in the snow surface were observed in the period from November to February, which is consistent with sublimation as a partial cause, although greater densification induced by summer warmth is also likely.

As part of an overall water budget calculation, it was estimated [King et al., 1996] that sublimation from the snow surface at Halley amounted to only about $4 \mathrm{~mm}$ water equivalent during the months of March to August. Deposition of hoar frost to the surface was larger (over $8 \mathrm{~mm}$ water equivalent) in these months. Both these numbers are rather small and would lead to a small effect (1-2\%) on snow concentrations. A calculation using such detailed data has not been made for the summer. One earlier estimate suggested that sublimation at Halley, concentrated in November to February, might amount to between 3 and $7 \mathrm{~cm}$ water equivalent [Limbert, 1963]. This is equivalent to about $20-50 \%$ of the net snow accumulation during the same 4 months and could therefore be a significant factor in the concentrations eventually seen for this period. Preliminary calculations (J.C. King, personal communication, 1997) confirm that sublimation rates of order 1 $\mathrm{mm} \mathrm{d}^{-1}$ might occur during summer. Averaged over the year, this is not a major factor, compared to an average annual accumulation (data from snow stake measurements, 1973-1989) of $32.4 \mathrm{~cm}$ water equivalent [King et al., 1996]. In this section, we have not considered the possible effect of sublimation from blowing snow, which will be discussed later.

\section{Fog Deposition}

During 1991, fogs were recorded in the meteorological record at Halley 134 times (3-hourly observations) on 65 separate days. This included 79 observations, on 41 days, when the codes for "fog, depositing rime" were used. It has previously been observed that the concentrations of chemicals in fog can exceed those in snow [Davidson et al., 1996]. For instance, the geometric mean concentrations for a period from May to July 1993 at Summit, Greenland, were higher in collected fog than in collected fresh snow by factors of 4.7 for sulphate and 1.7 for sodium [Bergin et $a l ., 1995 \mathrm{~b}]$. As a result, fogs may have a disproportionate effect on chemical deposition to the snow surface.

\subsection{Experimental Estimates of Fog Deposition}

In order to assess the possible influence of fog deposition at Halley, we consider only the days when rime was said to be depositing. Our analysis is complicated by the fact that other processes may be occurring simultaneously. Of the 41 days involved, only 12 had positive accumulations at our snow stake, while 7 had negative accumulations, and the rest had no observed accumulations. The zero or negative values could indicate that some of the rime deposits were very minor, or that sublimation was occurring at another part of the day, or that low-density rime was removed by wind after deposition. We also have no direct measure of chemical concentrations in the rime alone, but we know that the concentrations in surface snow on the days when riming occurred do not appear unusual compared to other days.

We can estimate the influence of rime in two ways. For the first method, we use our surface snow values, comparing the day after rime deposits have occurred with the day before. Apart from 1 day when snowfall and drift also occurred, all the riming days have accumulations at or below 1 centimeter, the depth of our sampler. Therefore the material deposited as rime should be recorded in our sample, even if subsequent sublimation has also occurred. The density of rime is rather low, so we take it as $300 \mathrm{~kg} \mathrm{~m}^{-3}$ $\left(0.3 \mathrm{~g} \mathrm{~cm}^{-3}\right)$. We assume that our sampler takes the top centimeter of snow, so that we collect $0.3 \mathrm{~g} \mathrm{~cm}^{-2}\left(3 \mathrm{~kg} \mathrm{~m}^{-2}\right)$. Then

$$
F_{f}=\rho\left(C_{n}-(1-A) C_{n-1}\right)
$$

where $F_{f}$ is the fog flux for the day $\left(n \mathrm{n} \mathrm{m}^{-2}\right), \rho$ is the mass collected per unit area $\left(3 \mathrm{~kg} \mathrm{~m}^{-2}\right), \mathrm{C}_{\mathrm{n}}$ is the snow concentration after the rime event ( $\left.\mathrm{ng} \mathrm{kg}^{-1}\right), \mathrm{C}_{\mathrm{n}-1}$ is the concentration before the rime event, and $A$ is the daily accumulation in centimeters (strictly the ratio of the daily accumulation to the thickness of the sampled layer). If $\mathrm{A}<0$, 
we set it to zero, and for $A>1$, we set it to 1 . Summing only the positive values of $\mathrm{F}_{\mathrm{f}}$ over the year 1991, and comparing this to the total fluxes derived from the concentrations in accumulated snow, we find that the fog flux can only be a maximum of between 5 and $7 \%$ of total accumulation for each ion. In fact, this figure is likely to be a large overestimate, since our method will have included the effects of any dry deposition, snow deposition, and sublimation on these days. In addition, because our use of positive values only ignores the large natural variability of snow concentrations, we are biasing the result to give a larger influence of fog than is realistic.

\subsection{Model Estimate of Fog Deposition}

A second estimate can be made using aerosol concentrations and a model [Bergin et al., 1995a; Davidson et al., 1996]. This model assumes that, during a fog event, a fraction of available aerosol within the height of the fog is taken up by fog droplets and removed to the surface by settling of the droplets. Then

$$
F_{f}=h_{\mathrm{f}} R C_{\text {uir }}\left(1-\exp \left(-\mathrm{V}_{\mathrm{s}} \mathrm{t} / \mathrm{h}_{\mathrm{f}}\right)\right)
$$

where $F_{f}$ is the chemical flux (ng m${ }^{-2} s^{-1}$ ) to the surface during the fog event, $h_{f}$ (meters) is the height of the fog, $R$ is the fraction of aerosol taken up by the fog droplets, $C_{\text {arr }}\left(\mathrm{ng} \mathrm{m}^{-3}\right)$ is the concentration of the chemical in air at the start of the fog event, $V_{s}$ $\left(\mathrm{m} \mathrm{s}^{-1}\right)$ is the settling velocity, and $\mathrm{t}$ (seconds) is the time for which the fog persists. To get an upper limit, we choose to set $R=1$, $\mathrm{h}_{\mathrm{f}}=150 \mathrm{~m}$ (a figure considered suitable for Summit in Greenland [Davidson et al., 1996]), and $\mathrm{V}_{\mathrm{s}}=0.7 \mathrm{~cm} \mathrm{~s}^{-1}$ (corresponding to a droplet diameter of $15 \mu \mathrm{m}$ ). We use the air concentration of the day before the fog event and take $t$ to be 3 hours for each observation of riming fog. The calculation gives an annual deposition in fogs for 1991 of only $56 \mathrm{ng} \mathrm{cm}^{-2}$ for $\mathrm{Cl}^{-}$and still smaller values for all other ions. This represents only just over $0.1 \%$ of the total deposition for each ion for the year. If we assume that all fogs were in fact depositing rime, we could increase the number by about $50 \%$. The amount of fog deposition can only be increased further by significantly increasing both the thickness of the fog and the settling velocity. This result is not in fact surprising, since we already know that a deposition velocity of $1 \mathrm{~cm} \mathrm{~s}^{-1}$ (used in dry deposition calculations) applied throughout the year leads to only a few percent of the total deposition, and fogs were only present at Halley for about $5 \%$ of the year (riming fogs for $3 \%$ of the year).

On the basis of the model results, fog deposition seems completely negligible at Halley. The only possibility that this is incorrect would be if aerosol concentrations above the surface were very significantly higher than those measured at ground level. Even then, from our fresh snow data, we can constrain the effect of fog to be less than a few percent of the total inventory to the snow surface each year.

\section{Wet Deposition}

Wet deposition includes several processes in and below the cloud, but should be observed as the flux of chemicals in fresh snow. Concentrations in fresh or newly accumulated snow are available from Halley, Neumayer, and Dumont d'Urville. At each site, we have looked at the relationship between snow and air concentrations, using the average of snow concentrations for a single snowfall event, and aerosol concentrations for the period including, or immediately preceding, the snowfall collection.

\subsection{Dumont d'Urville}

At Dumont d'Urville, 117 separate snowfall events were sampled between February 1991 and January 1994. Between two and four samples have been averaged for each event. Because snow melts in summer at this station, there are virtually no samples between January and March. The snow samples were matched to the aerosol sample nearest (but preceding or including) the event. In some cases, the aerosol sample covered a period of up to 4 days preceding the snow sample. This will obviously reduce the likelihood of capturing the relationship between snow concentrations and aerosol concentrations that might be quite episodic in nature.

It is clear (Figure 4) that, although there is some correlation between fresh snow and aerosol concentrations for MSA, there is no correlation for sea-salt ions, nor for ammonium and other chemicals that derive from a local penguin source [Legrand et al., this issue]. The better correlation for MSA (Figure 5) probably reflects a similar and strong seasonality, rather than a good event by event relationship. Despite the poor correlation, we have calculated the scavenging ratio (W) according to equation (4) for each event. The results are summarized in Table 2. No seasonal pattern in the scavenging ratio can be discerned against the very large scatter of the data. The $\mathrm{W}$ values for each ion are approximately lognormally distributed, so we present them as geometrical means. Median values are rather similar to the geometrical means, but we emphasize that the $\mathrm{W}$ values range over 2 orders of magnitude for MSA and 4 orders of magnitude for seasalt ions. Where there was a significant correlation coefficient, the gradient of the best fit was used as a measure of $\mathrm{C}_{\mathrm{snow}} / \mathrm{C}_{\mathrm{ar}}$ in equation (4) to calculate a $\mathrm{W}$ value. The very high apparent scavenging ratios for sea-salt and penguin-related ions (such as ammonium) probably reflect direct fallout of large, very locally produced particles during storms and have no general significance.
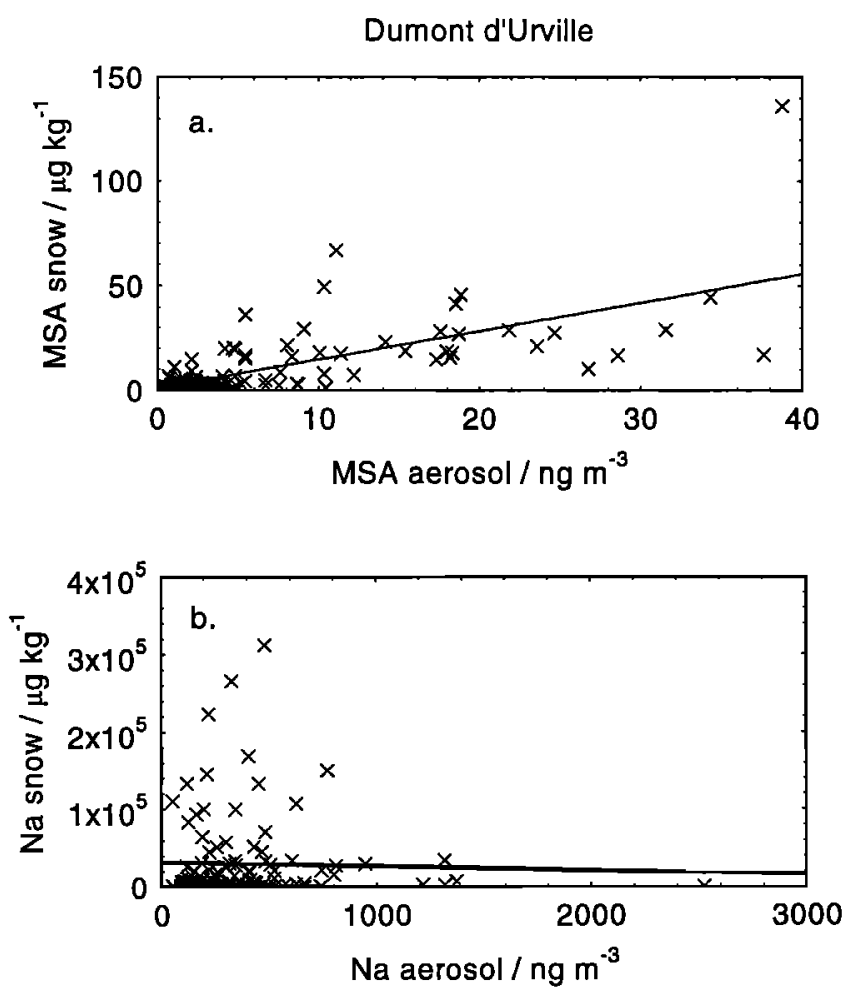

Figure 4. Plots of fresh snow concentrations for individual events over a 3-year period at Dumont d'Urville versus the closest available aerosol concentration (see text). (a) MSA and (b) Na. Other sea-salt ions give similar scattered plots to that from $\mathrm{Na}$. 


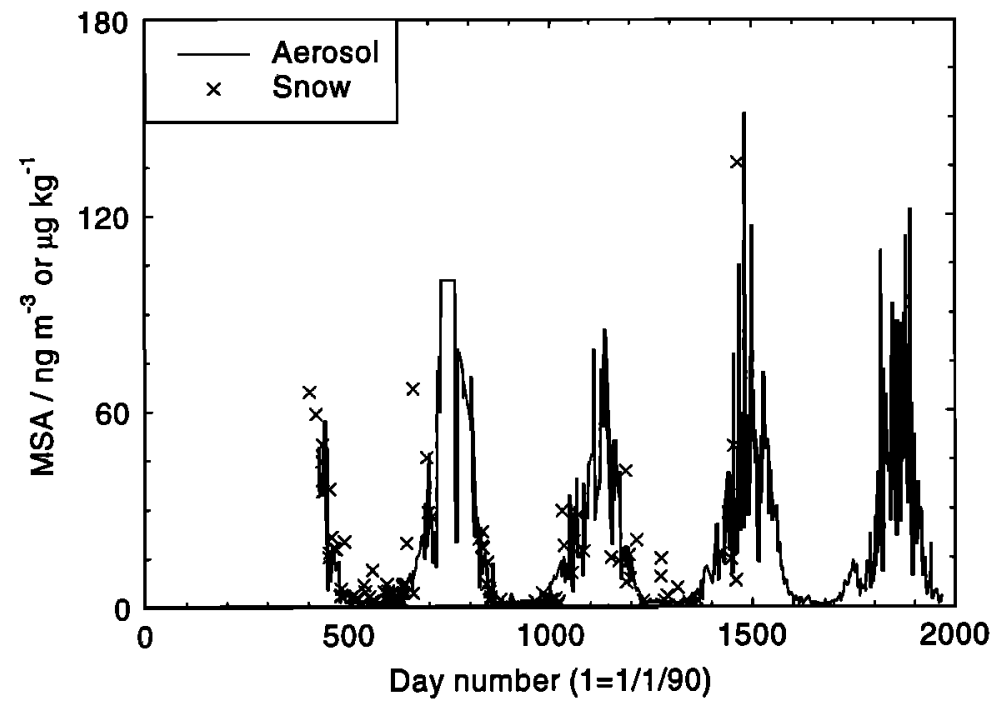

Figure 5. Fresh snow (crosses) and aerosol (line) concentrations of MSA at Dumont d'Urville. Day $1=1 / 1 / 90$.

\subsection{Neumayer}

At Neumayer, 118 snow events were sampled between February 1984 and December 1992. The corresponding aerosol samples covered periods of at least 1 week, and often 2 weeks or more, with the snow event occurring at any point within that period. It is unlikely that we could hope to capture the relationship between aerosol and snow concentrations where the concentrations are in any way episodic.
Again, only for MSA (and, though weaker, non-sea-salt sulphate), is there any significant correlation between fresh snow concentrations and the related aerosol concentrations. There is no significant correlation for sea-salt species or for ammonium. We have again calculated scavenging ratios which are very scattered (though less so than those at Dumont d'Urville). The $W$ values are approximately lognormally distributed, so we report the geometric means (which are generally within $10 \%$ of the median) in Table 2.

Table 2. Scavenging Ratios Calculated According to Equation (4) for Fresh Or Accumulated Snow at Three Antarctic Stations

\begin{tabular}{|c|c|c|c|c|c|}
\hline & MSA & $\mathrm{Cl}^{-}$ & $\mathrm{Na}$ & $\mathrm{NH}_{4}{ }^{+}$ & nss $\mathrm{SO}_{4}{ }^{20}$ \\
\hline $\begin{array}{l}\text { Dumont d'Urville } \\
\text { geometric mean } \\
\text { (Feb. } 1991 \text { to Jan. 1994) }\end{array}$ & $\begin{array}{l}1,590 \\
{[580 ; 4,300]}\end{array}$ & & $(29,310)$ & $(15,750)$ & \\
\hline $\begin{array}{l}\text { Dumont d'Urville } \\
\text { regression } \\
\text { (Feb. } 1991 \text { to Jan. 1994) }\end{array}$ & $\begin{array}{l}1,850 \\
{[ \pm 150]}\end{array}$ & & & & \\
\hline $\begin{array}{l}\text { Neumayer } \\
\text { geometric mean } \\
\text { (Feb. } 1984 \text { to Dec. 1992) }\end{array}$ & $\begin{array}{l}790 \\
{[280 ; 2,230]}\end{array}$ & $\begin{array}{l}2,860 \\
{[490 ; 16,700]}\end{array}$ & $\begin{array}{l}1,780 \\
{[370 ; 8,600]}\end{array}$ & $\begin{array}{l}1,260 \\
{[390 ; 4,020]}\end{array}$ & $\begin{array}{l}960 \\
{[330 ; 2,800]}\end{array}$ \\
\hline $\begin{array}{l}\text { Neumayer } \\
\text { regression } \\
\text { (Feb. } 1984 \text { to Dec. 1992) }\end{array}$ & $\begin{array}{l}860 \\
{[ \pm 100]}\end{array}$ & & & & $\begin{array}{l}940 \\
{[ \pm 130]}\end{array}$ \\
\hline $\begin{array}{l}\text { Halley } \\
\text { geometric mean } \\
\text { (Feb. } 1991 \text { to Sept. 1992) }\end{array}$ & $\begin{array}{l}3,100 \\
{[780 ; 12,300]}\end{array}$ & $\begin{array}{l}5,840 \\
{[1,460 ; 23,000]}\end{array}$ & $\begin{array}{l}8,300 \\
{[2,100 ; 33,200]}\end{array}$ & & $\begin{array}{l}3,270 \\
{[1,370 ; 7,800]}\end{array}$ \\
\hline $\begin{array}{l}\text { Halley } \\
\text { regression } \\
\text { (Feb. } 1991 \text { to Sept. 1992) }\end{array}$ & $\begin{array}{l}2,280 \\
{[ \pm 680]}\end{array}$ & $\begin{array}{l}1,630 \\
{[ \pm 330]}\end{array}$ & $\begin{array}{l}3,450 \\
{[ \pm 580]}\end{array}$ & & \\
\hline
\end{tabular}

Regressions used only where statistically significant. All regression coefficients (plus or minus standard error) are for lines forced through origin. The values in brackets represent unrealistic ratios due to very local production and deposition. For the geometric means, the values in square brackets are the values at \pm 1 geometric standard deviation. $\mathrm{NH}_{4}^{+}$was not measured in most samples at Halley, and $\mathrm{Cl}^{-}$was not measured in Dumont d'Urville snow. Because of the very high Na concentrations in Dumont d'Urville snow, nss $\mathrm{SO}_{4}{ }^{2-}$ in snow at this site is totally controlled by the way it is corrected for sea-salt, so we have not used these values. 

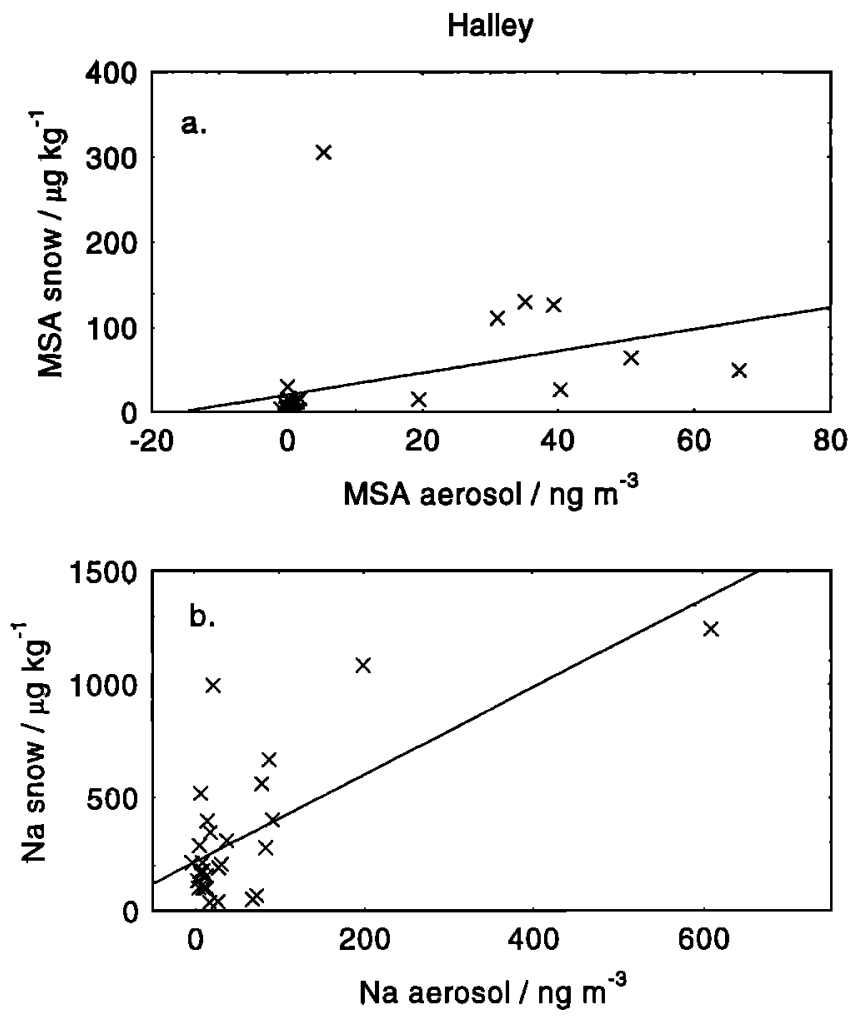

Figure 6. Plots of fresh snow concentrations for individual events over a 2-year period at Halley versus the aerosol concentration (generally for the preceding 24 hours, see text). (a) MSA and (b) Na.

No clear seasonal pattern emerges from the scatter. The higher mean ratio for $\mathrm{Cl}^{-}$in comparison to $\mathrm{Na}$ is probably related to the depletion of $\mathrm{Cl}^{-}$that has been recognized on summer filters at this station, and which may be partly an artefact of the long aerosol sampling times [Wagenbach et al., this issue].

\subsection{Halley}

At Halley, 65 accumulated snow events were sampled between July 1990 and September 1992. However, only from February 1991 (42 events) are aerosol data available. At Halley, a sequence of samples through the depth of newly accumulated snow was collected. Thus, for $10 \mathrm{~cm}$ of accumulation on a particular day, a sequence of six samples covering this depth was taken. Altogether 250 samples were taken over the 65 events. The variability of samples within a snowfall event (s.d. $28 \%$ for $\mathrm{Cl}^{-}$) is low compared to the variability between snowfall events (s.d. $116 \%$ for $\mathrm{Cl}^{-}$). This suggests either that individual snowfalls are quite uniform or (more likely) that the accumulation becomes well-mixed during drift and deposition. We have averaged the samples for each event to assign a single concentration to each. We then used the aerosol sample collected during the preceding 24 hours (occasionally 48 or 72 hours) for comparison. Thus the Halley samples have the advantage that the aerosol sample generally refers to the most narrow relevant time period, but they have the disadvantage that there is no attempt at differentiation between fresh snowfall and accumulation due mainly to drifting and blowing snow. In fact, it is likely that both occur during most significant accumulations.

For both MSA and sea-salt ions, a weakly significant correlation between snow concentrations and aerosol concentrations is found. However, it is clear (Figure 6) that the data are very scattered, and the correlation relies on a small number of points. The $W$ values are approximately lognormally distributed and are presented as geometric means in Table 2. Only values where both aerosol and snow concentrations were above the detection limit (twice the s.d. of the field blank) are used in calculating W. No seasonal signal in $\mathrm{W}$ can be discerned from the scattered data. The big difference between W values calculated by two methods for Halley illustrates the extreme uncertainty of the numbers obtained.

\subsection{Significance of $W$ Values}

We can compare the $W$ values presented in Table 2 with those found in the literature. The very few literature data are given in Table 3. Other estimates for the polar regions seem to involve only average aerosol concentrations (for snowfall and nonsnowfall periods) and average ice core concentrations, and therefore a scavenging ratio cannot be derived. The previous data are so few that they offer little help in interpreting our data. However, we note that the low values seen for sulphate in Greenland are not observed in coastal Antarctica. In general, sea-salt species appear to give higher scavenging ratios than do MSA or sulphate. This may reflect the presence of larger particles due to the relatively local sea-salt source, leading to more efficient scavenging. It is difficult to explain the differences for MSA between the three sites. This may reflect to some extent the different sampling procedures. On the one hand, the relevant aerosol concentration is "diluted" by the relatively long sampling times at Dumont d'Urville and especially Neumayer. On the other hand, the Halley samples probably mainly include drifted snow, which could lead to extra scavenging after the initial deposition.

Despite the discussion of the last paragraph, we feel rather uncomfortable trying to discuss the causes of variations in $\mathrm{W}$ at the

Table 3. Scavenging Ratios Reported in Literature for Antarctica and Greenland

\begin{tabular}{llcc}
\hline & $\mathrm{Na}$ & $\mathrm{SO}_{4}{ }^{2-}$ & $\mathrm{Ca}$ \\
\hline $\begin{array}{l}\text { Antarctic Peninsula } \\
\text { five summer snowfalls derived from } \\
\text { data of Dick and Peel [1985] }\end{array}$ & $2400 \pm 1200$ & & $3600 \pm 1400$ \\
$\begin{array}{l}\text { Dye 3, Greenland } \\
\text { three summer snowfalls } \\
\text { [Davidson et al., 1985] }\end{array}$ & $2000 \pm 1200$ & $180 \pm 120$ & \\
$\begin{array}{l}\text { Summit, Greenland } \\
\text { eight summer snowfalls } \\
\text { [Davidson et al., 1996] }\end{array}$ & & \\
\hline
\end{tabular}

All values are arithmetic means and standard deviations. 
three sampling sites. The poor correlation between snow and aerosol concentrations suggests that the scavenging ratio, as measured here, is really not a meaningful concept. Although other factors (such as particle size, cloud height, and humidity) must be relevant, it is obvious that aerosol concentration should have a major influence on snow concentrations. The reasons for the poor correlations we see could be the following

1. Ground-level concentrations may not be representative of concentrations at higher level, at least during snowfall events. One could certainly imagine that ground-level concentrations would be reduced during blowing snow events. This would have the general effect of raising apparent scavenging ratios and can only be overcome by sampling above any likely blowing snow. This effect should be less important at Neumayer, where sampling was at $7 \mathrm{~m}$ above the snow surface. We note that even for MSA, the calculated average $W$ values for the three sites (800-3000) would, for a snow accumulation of $1 \mathrm{~cm}$ water equivalent, imply cleansing of a column $6-23 \mathrm{~km}$ in height. These unrealistically large heights reinforce the idea that the relevant aerosol concentrations (aloft) may be larger than those at ground level that we are measuring. We would expect this factor to be more important in winter, when inversions are stronger and deeper.

2. The concentrations in rather long aerosol sampling periods may not be representative of aerosol concentrations immediately before and during a snowfall. Again, this seems likely, since by definition the air mass during a precipitation event is likely to be different from that at other times.

3. Our snow samples, especially at Halley, may not be fresh snow and therefore may contain a memory of the aerosol concentration during a previous snowfall event.

These problems appear rather hard to overcome. They suggest that successful scavenging ratio measurements at these sites will only be possible by collecting samples at the top of tall towers to ensure fresh snowfall is collected and using very short pumping times to get data truly relevant to the snowfall event.

With the data available at present, it is quite impossible to make any statements about how $W$ values vary under different conditions and therefore to assess the effect of changing climate on scavenging ratios. However, we can take a more global view of the data to assess how ice core concentrations and aerosol concentrations are in general related to each other. This will be done in section 8 .

\section{Blowing and Drifting Snow}

We now briefly discuss what effect drifting and blowing snow could have on the concentrations eventually seen in ice cores. Drifting snow is reported in more than $40 \%$ of all meteorological observations at Neumayer, $13 \%$ at Dumont d'Urville, and $18 \%$ at Halley [König-Langlo et al., this issue]. These events can have three important effects on snow concentrations: (1) snow drift can scavenge particles from the lower levels of the troposphere, increasing concentrations; (2) sublimation of water vapor from drifting snow can lead to increased concentrations; (3) movement of snow can lead to redistribution of snow; snow can be moved from upwind to a new location, or snowfalls can be removed completely from the record. We can make estimates of the importance of the first two processes, and comment on the likely importance of the third process.

During 1991, drifting snow (i.e., snow generally below eye level) was reported in at least one 3-hourly observation on 82 days, and blowing snow was reported on a further 82 days at Halley. We have made an estimate of the possible role of direct scavenging by drifting and blowing snow by assuming that drifting snow completely cleanses a $5 \mathrm{~m}$ thick layer of air, and blowing snow cleanses a $50 \mathrm{~m}$ layer, on each day that it occurs. Using the aerosol concentrations on the relevant days in 1991, the flux to the surface from such cleansing amounts to approximately $0.1 \%$ of the annual deposition in accumulating snow for each ion. Even if the height scavenged is increased to quite unreasonable amounts (for instance, a height of $500 \mathrm{~m}$ on every day even with slight drift would still give only about a $2 \%$ contribution), direct scavenging by drifting and blowing snow must be a negligible influence on the annual flux of chemistry. Using a more complicated model, the same result has previously been reported for south pole [Harder et al., 1996]. The only ways to increase the effect of scavenging by blowing snow would be (1) if the near-surface air was being replenished with chemicals rapidly from above (as might be the case for very large particles discussed in section 4.2), or (2) if the air being scavenged was far more concentrated in chemistry than was the air we measured, either because air near the surface was more depleted than the average air column being scavenged, or because the snow particles had already passed over (and scavenged) a more concentrated air mass (for instance directly over the sea for marine ions).

Sublimation of water vapor from drifting snow could lead to a considerable enhancement in chemical concentrations, at least until the point when sublimation is so complete that the aerosol is rereleased to the atmosphere. For Halley, calculations have been made using observed meteorological variables, of the sublimation rate from blowing snow during the autumn and winter period [King et al., 1996]. The calculated sublimation rate during this 6-month period is $3.71 \mathrm{~mm}$ water equivalent, which is about $1.5 \%$ of the net accumulation. Although higher sublimation rates might be possible in the summer months, it appears that this will not have an important effect on chemical concentrations at this site. Clearly, it could be much more significant at low accumulation sites and at windier sites. The result is considerably lower than the estimate made for coastal Antarctica using a general circulation model (GCM) simulation and a simple sublimation model [Pomeroy and Jones, 1996]. With an assumed fetch length of $10 \mathrm{~km}$, the sublimation estimate in this latter model was $244 \mathrm{~mm}$ water equivalent per year. The main reason for the difference between the two estimates is probably the relative humidity used. Observation suggests that, when blowing snow does occur, the lowest few meters of the atmosphere are very close to saturation with respect to ice [King et al., 1996], and this causes relatively low sublimation rates.

The third effect of blowing and drifting snow is to move snow around. That this can have a significant effect on concentrations at a given site is evident. For example, during 1991 at Halley, there were five occasions when the snow surface reduced by $5 \mathrm{~cm}$ or more from 1 day to the next and 22 occasions when the negative accumulation was more than $1 \mathrm{~cm}$. In these cases, snowdrift is removing entire snowfalls from the accumulated record. There may equally be occasions when snowfalls that did not take place at Halley are blown into the record. There is a general assumption that snowdrift should overall be neither convergent or divergent and therefore on average have no effect on snow accumulation. This may be true at inland sites. However, at Halley, sandwiched between a slope with high-speed katabatics, and the sea, which can generally not be a source for previously deposited snow, this assumption need not be true. Furthermore, the sea-salt content of snow originating just a few kilometers nearer the sea than Halley is expected to be considerably higher than that at Halley. For this reason, westerly winds (direction of coastline) with blowing snow are expected to bring snow more concentrated in sea-salt to Halley, while easterlies should bring slightly less concentrated snow to the site. We cannot make any estimate of the importance of this effect at this stage, but it is a complication that may not be present at inland sites. 


\section{General Overview of Relationship Between Snow and Aerosol Concentrations}

The previous sections have indicated that the chemistry deposited in fresh or newly accumulated snow (which we have treated as wet deposition) is the main source of chemical flux to the snow surface at Halley (see Table 1). However, there was a poor relationship between snow concentrations and aerosol concentrations on the same days. There is nonetheless some relationship between periods of high aerosol concentrations and periods of high snow concentrations in accumulating snow (Figure 7). For MSA, the similarity derives from the common seasonality. For $\mathrm{Cl}^{-}$, a similar common seasonality is seen, but there are periods of high aerosol concentration that are not echoed in the accumulating snow, and high concentrations in accumulating snow seem sometimes to be associated with days of low aerosol concentration (albeit in periods of average high aerosol concentration).

This pattern is perhaps seen more clearly in Figure 8 . This shows that surface snow concentrations (including all daily samples, whether there was significant accumulation or not) really do respond to most aerosol events (for instance between days 500 and 600 , only the aerosol peak around day 570 shows no analogous and simultaneous increase in the surface snow record). However, the period for which they stay high, and the phase between aerosol and snow concentration increases, is not consistent. Significant snow accumulations occur only on the days shown by grid lines in Figure 8, and this imposes one more barrier for the comparison of aerosol and accumulated snow concentrations. The surface snow record is also affected by negative accumulations and, for instance, a large negative accumulation on day 592 probably accounts for the reduction in concentration seen then. Looking at Figure 8, it appears that, when snow concentrations do respond to an aerosol event, it is with an apparent scavenging ratio for $\mathrm{Cl}^{-}$that is rather high (in the range 3000 to 6000 ), not dissimilar to the high values we have already derived (Table 2 ).

Overall, our interest is in the relationship between (1) accumulated snow that remains and joins the ice core record and (2) aerosol concentrations. It appears that the aerosol concentration does affect snow concentrations, as we would expect. However, the frequency and timing (relative to aerosol events) of both positive and negative accumulation events has a large impact on the eventual record. For a species that has a strong seasonal signal, such as MSA, we can reasonably expect the relationship to be well-preserved despite these factors. For an episodic species such as sea-salt, it is harder to be confident that changes seen in the snow record really arise from changes in aerosol concentration, rather than from quite subtle changes in the relationships between precipitation, chemical events, and snowdrift events. An additional confusion at Halley arises from the large spatial gradients expected so near to the sea.

\section{Translation to Ice Core Record}

In order to see whether the accumulated snow translates correctly to an ice core record, and particularly to look for any postdepositional effects [Wolff, 1996], it is necessary to compare the record of accumulated snow with that of the firn core collected at Halley. To achieve this, the accumulated snow data from Halley were compiled, using only samples within the depth of fresh accumulation as recorded at the snow stake. Where accumulations of more than $0.5 \mathrm{~cm}$ were recorded, but no accumulated snow
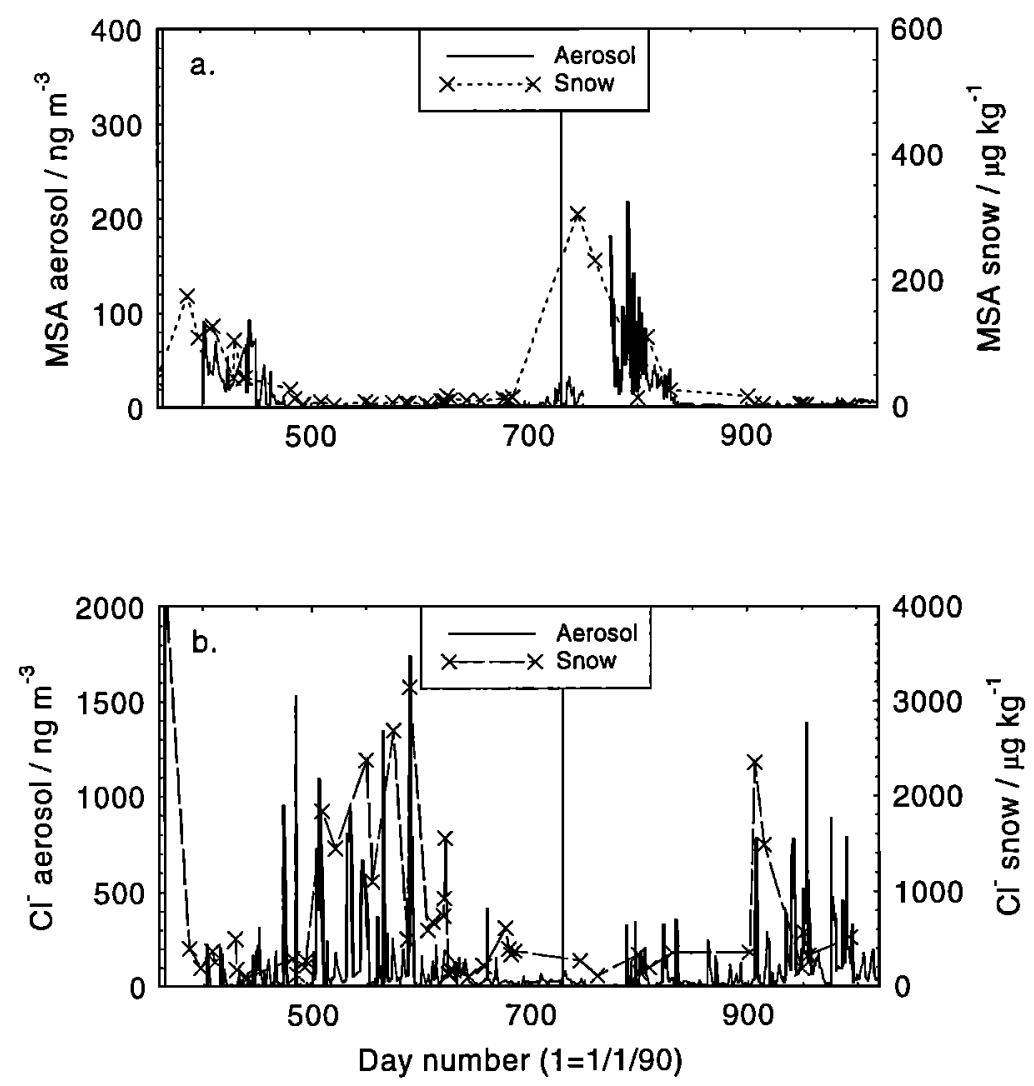

Figure 7. Aerosol and accumulated snow concentrations for 1991 and most of 1992 at Halley. The accumulated snow concentrations are the mean concentrations for each accumulation event. (a) MSA and (b) $\mathrm{Cl}^{\text {- }}$. 


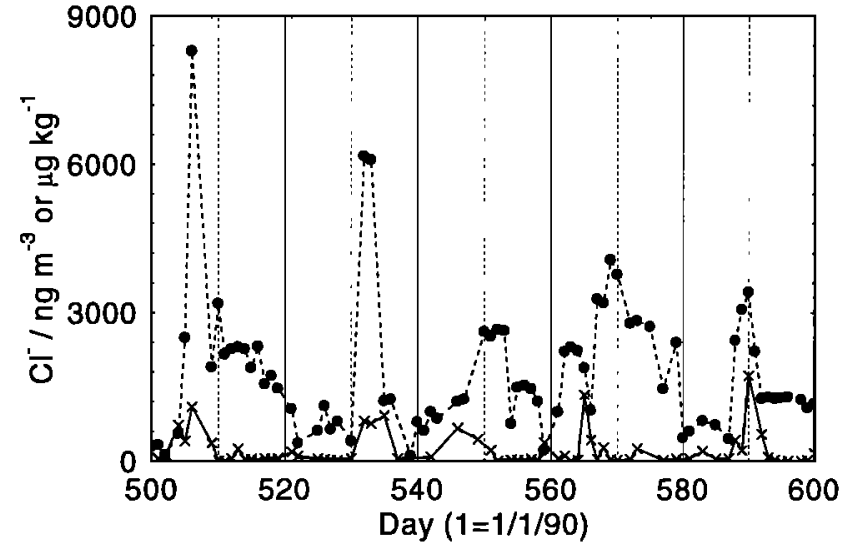

Figure 8. Surface snow and aerosol concentrations of $\mathrm{Cl}^{-}$at Halley for a detailed section from winter 1991. The grid lines are the dates of significant snow accumulation. Snow concentrations are dashed lines; aerosol concentrations are solid lines.

samples were collected, a surface snow sample was added to the record (until the end of 1991). In some cases, a positive accumulation was followed rapidly by a negative accumulation (Figure 1): in these cases, the appropriate samples from the top of the accumulated snow were discarded from the data set. In this way, a record of the snow that should have actually accumulated at the site was compiled. This has been compared with the fim core from the Halley 5 site (Figure 9).

The accumulated snow and firn core records have been plotted such that they can be relatively easily compared. The apparent compression of peaks into a shorter depth in the core (distances reduced to about $75 \%$ of original) is what is expected from the densification of fresh snow in the first 1-2 years. In the $\mathrm{Cl}^{-}$record, it is obvious that the main features recorded in the accumulated snow were indeed seen in the core. For the big peak at about 2.3 $m$ depth in the core, the lower (by about $30 \%$ ) concentrations in the core probably reflect the fact that the accumulated snow was collected at the Halley 4 station, while the core was collected 2 years later at Halley 5 station, farther from the ice shelf edge (although we cannot rule out the possibility that some gas phase loss of $\mathrm{HCl}$ could have occurred). This reinforces our belief that the sea-salt signal is relatively local. We also note again the extreme influence of individual events in the record: over $50 \%$ of the $\mathrm{Cl}^{-}$deposited in the 2.5 years of the accumulated snow record appears in this peak, representing just $5 \%$ of the snowfall, and just over a week in time. One major $\mathrm{Cl}^{-}$event (at $360 \mathrm{~cm}$ of accumulated snow) has no obvious counterpart in the firn core, and some minor peaks can also not be identified.

Turning to the MSA record, the situation is less clear. In this case, the accumulated snow is dominated by the summer/spring peaks in MSA, and we expect the same in the ice core. Because the

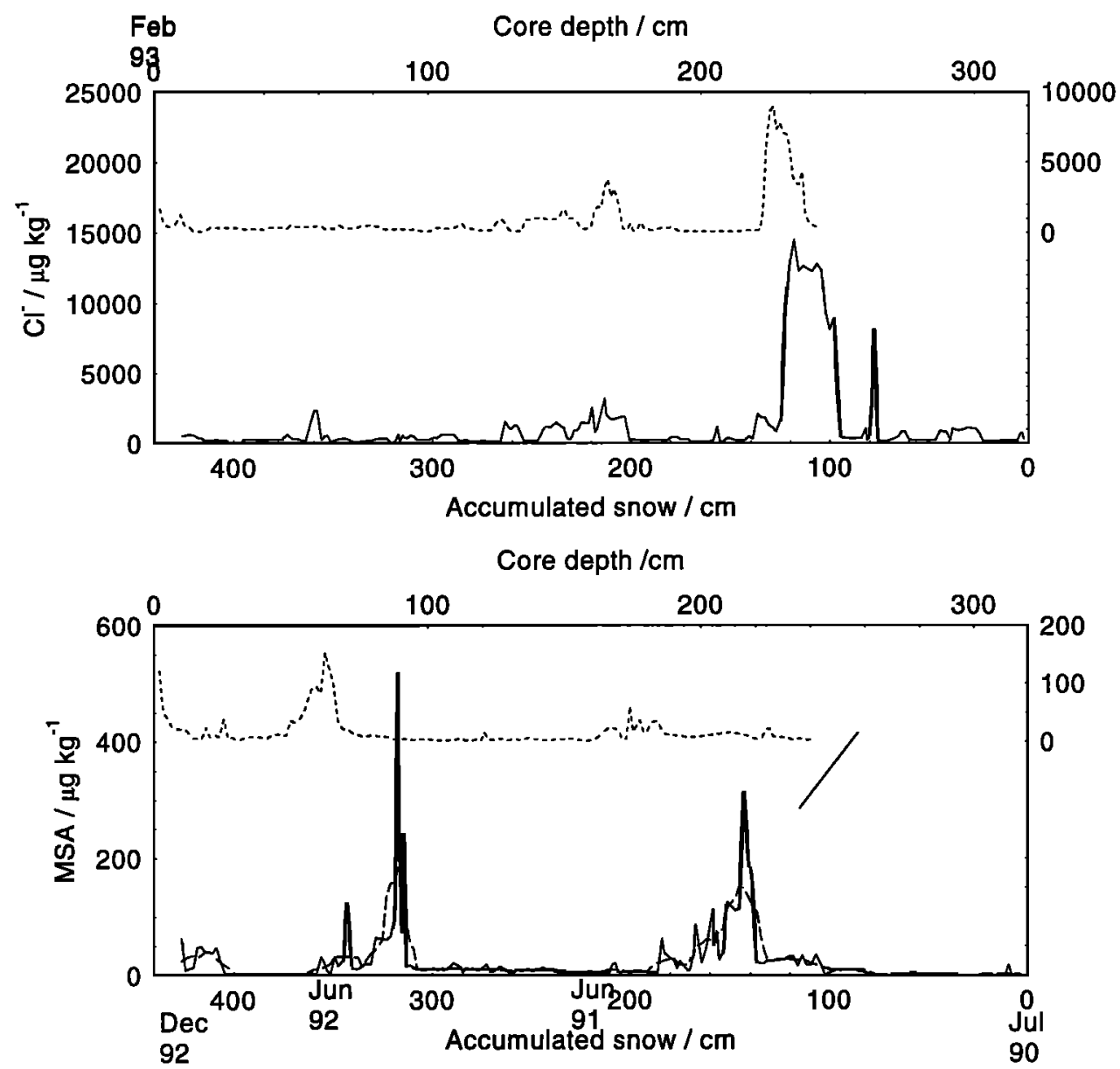

Figure 9. Profiles of snow that appeared to accumulate (see text for explanation) at Halley from July 1990 to December 1992 (solid line, lower and left axes), and of a firn core drilled at Halley in February 1993 (short-dashed line, upper and right axes). (top) $\mathrm{Cl}^{-}$and (bottom) MSA. The longer-dashed line for MSA is a 7-point (equivalent to about $10 \mathrm{~cm}$ ) running mean of the accumulated snowfall. 
accumulated snow record ends in December 1992, we do not see the main rise at the top of the firn core. However, the peak that represents summer 1991/1992 is well-represented in the core. Although the maximum in the accumulated snow record is more than 3 times the maximum signal in the firn core, smoothing of the accumulated snow record can reproduce the magnitude and width of the peak seen in the core rather well. This smoothing may be a result of snowdrift reworking the snowfall or of genuine smoothing through diffusion in fim.

It is more difficult to understand the mismatch in the summer 1990/1991 peak. The maximum concentration in the accumulated snow (at approximately $150 \mathrm{~cm}$ in that record) is 5 times higher than the maximum in the core, and smoothing cannot come close to reproducing the core values. Furthermore, given our rather definite match of the $\mathrm{Cl}^{-}$peaks, and the fact that the MSA peak in the core is only a few centimeters above the winter $1991 \mathrm{Cl}^{-}$ maximum, while the MSA peak in the accumulated snow record occurs just a few $\mathrm{cm}$ after the (November 1990) $\mathrm{Cl}^{-}$maximum, it seems that the MSA peak is occurring at a different time as well as being of a far lower magnitude in the core. It is possible to imagine that MSA is being partly lost and partly moved (upward) in a postdepositional process, which might be linked to the relocation of MSA from summer to winters that occurs at some ice core sites [Mulvaney et al., 1992; Wagenbach et al., 1994]. However, such a strong migration after less than 2 years has not been observed previously. This explanation fails because non-sea-salt sulfate exhibits the same behavior, and it has never been observed to migrate in cores. Additionally, the MSA firn core concentrations (both annual and summer maximum) for the year 1991 seem very low for a site so near to the coastline (in comparison, for instance, to sites farther inland on the Ronne-Filchner Ice Shelf [Minikin et al., 1994]. The more likely explanation seems to be that the snow that appears in the accumulated snow record between 140 and 160 $\mathrm{cm}$ or perhaps $170 \mathrm{~cm}$ simply does not appear in the firn core record. This is consistent with the $\mathrm{Cl}^{-}$record, where some small but significant peaks between 130 and $160 \mathrm{~cm}$ in the accumulated snow record also fail to appear in the core.

It therefore appears that only the autumn tail of the 1991 MSA peak is preserved in the firn core. This might be due to reworking of snow during snowdrift or may reflect a difference in accumulation between the sampling site at Halley 4 station and the core site at Halley 5 station. In any case, it provides a warning that even quite long-lasting seasonal features in the aerosol record, that show up in fresh snow, may not be well-recorded in a core. This implies that dating by single parameters, however well-defined their seasonal cycle, is dangerous, and that single-year averages from single sites can also fail to give a reliable record of the atmosphere. Even at a site like this, with relatively high snow accumulation rates, significant parts of the year can be poorly represented in the firn and ice core record. A larger study, involving a range of cores, and preferably more snow sampling sites, would be needed to define how often problems such as these occur.

\section{Conclusion}

Although a number of processes can be considered, it appears (with the exception of very large, locally produced particles, which may be important for sea-salt aerosol) as if the key deposition process for Halley, and probably for all of coastal Antarctica, is wet deposition. Other processes may be more important at inland sites, with low snow accumulations. This paper has highlighted the difficulties, even with a very extensive year-round data set, of studying many of the processes in an area where the surface changes frequently.
For coastal Antarctica, the factors controlling the strength of wet deposition need far more study. The poor correlations we have found between aerosol and snow concentrations have highlighted the need for more sophisticated experimental designs. In particular, measurements at higher levels in the atmosphere are certainly needed if wet deposition is to be better understood. This is particularly so in areas where drifting and blowing snow are important.

With present knowledge, it would be possible, for a given ion, to use present-day gross ratios between air and snow concentrations, along with ice core concentrations, to estimate atmospheric concentrations at some time in the past. However, to do this would make a number of assumptions: (1) that the same processes (i.e., wet deposition) prevailed in the past, (2) that other meteorological factors (such as amount of snow drift) affecting the vertical profile of chemistry remained the same, and (3) that the frequency and seasonal distribution of precipitation remained the same. Our estimates in this paper suggest that wet deposition is so strongly dominant that it is likely to have remained the key process under all reasonable past variations; assumption 1 is probably correct. However, there is no reason why the other two assumptions should be correct. The likely effect of this concern cannot be estimated until we have a better knowledge of the existing vertical profiles and climatology of precipitation distribution.

Our experiments have highlighted a number of methods that are unlikely to be successful in studying air-snow transfer at coastal sites and led to some suggestions about strategies that could lead to more quantitative understanding of key processes. For the future, efforts are îkely to move to iniand areas, where several deep cores are planned or underway. The low snow accumulation rates in central Antarctica will pose new samplung problems and also make it unlikely that studies can be focused on only one deposition mechanism. However, with more stable meteorological conditions and a probable lower influence of drifting snow, some of the problems encountered at the coast may be avoided.

Acknowledgments. We thank all the personnel at Halley, Neumayer, and Dumont d'Urville who assisted with sample collection. We acknowledge Francois Ducroz for the supply of Dumont d'Urville data. This program was funded in part by the European Community STEP program, under the project Polar Atmospheric Chemistry.

\section{References}

Bales, R. C., and E. W. Wolff, Interpreting natural climate signals in ice cores, Eos Trans. AGU, 76, 477-483, 1995.

Bergin, M. H., J.-L Jaffrezo, C I. Davidson, R. Caldow, and J. Dibb, Fluxes of chemical species to the Greenland ice sheet at Summit by fog and dry deposition, Geochim. Cosmochim. Acta, 58, 3207-3215, 1994.

Bergin, M. H., C I. Davidson, J. E. Dibb, J. L. Jaffrezo, H. D. Kuhns, and S. N. Pandis, A simple model to estimate atmospheric concentrations of aerosol chemical species based on snow core chemistry at Summit, Greenland, Geophys. Res. Lett., 22, 3517-3520, 1995a.

Bergin, M. H., J.-L. Jaffrezo, C. I. Davidson, J. E. Dıbb, S. N. Pandis, R. Hillamo, W. Maenhaut, H. D. Kuhns, and T. Makela, The contributions of snow, fog, and dry deposition to the summer flux of anions and cations at Summit, Greenland, J. Geophys. Res., 100, 16,275-16,288, 1995b.

Davidson, C. I., Mechanisms of wet and dry deposition of atmospheric contaminants to snow surfaces, in Dahlem Konferenzen: The Environmental Record in Glaciers and Ice Sheets, edited by $\mathrm{H}$. Oeschger and C. C. Langway Jr., pp. 29-51, John Wiley, New York, 1989

Davidson, C. I., S. Santhanam, R. C. Fortmann, and M. P. Olson, Atmosphenc transport and deposition of trace elements onto the Greenland Ice Sheet, Atmos. Environ., 19, 2065-2081, 1985.

Davidson, C. I., et al., Chemical constituents in the air and snow at Dye 3, Greenland, I, Seasonal variations, Almos. Environ., Part A, 27, 27092722, 1993a. 
Davidson, C. I., J.-L. Jaffrezo, M. J. Small, P. W. Summers, M. P. Olson, and $R$. D. Borys, Trajectory analysis of source regions influencing the south Greenland ice sheet during the Dye 3 gas and aerosol sampling program, Atmos. Environ., Part A, 27, 2739-2749, $1993 \mathrm{~b}$.

Davidson, C. I., M. H. Bergin, and H. D. Kuhns, The deposition of particles and gases to ice sheets, in Chemical Exchange Between the Atmosphere and Polar Snow, NATO ASI Ser. I, vol. 43, edited by E. W. Wolff and R. C. Bales, pp. 275-306, Springer-Verlag, New York, 1996.

Dibb, J. E., Overview of field data on the deposition of aerosol-associated apecies to the surface snow of polar glaciers, particularly recent work in Greenland, in Chemical Exchange Between the Atmosphere and Polar Snow, NATO ASI Series I, vol. 43, edited by E. W. Wolff and R. C. Bales, pp. 249-274, Springer-Verlag, New York, 1996.

Dick, A. L., A simple model for air/snow fractionation of aerosol components over the Antarctic Peninsula, J. Atmos. Chem., 11, 179-196, 1990.

Dick, A. L., and D. A. Peel, Trace elements in Antarctic air and snowfall, Ann. Glaciol., 7, 12-19, 1985.

Ducroz, F., Étude de la composition chimique de la basse atmosphère des régions côtières Antarctiques, Ph.D. thesis, Lab. de Glaciol. et Géophys.de l'Environ., Grenoble, 1996.

Harder, S. L., S. G. Warren, R. J. Charlson, and D. S. Covert, Filtering of air through snow as a mechanism for aerosol deposition to the Antarctic ice sheet, J. Geophys. Res., 101, 18,729-18,743, 1996.

Ibrahim, M., L. A. Barrie, and F. Fanaki, An experimental and theoretical investigation of the dry deposition of particles to snow, pine trees and artificial collectors, Atmos. Environ., 17, 781-788, 1983.

Jaffrezo, J.-L., and C. I. Davidson, The Dye 3 gas and aerosol sampling program (DGASP): An overview, Atmos. Environ., Part A, 27, 27032707, 1993.

King, J. C., P. S. Anderson, M. C. Smith, and S. D. Mobbs, The surface energy and mass balance at Halley, Antarctica during winter, J. Geophys. Res., 101, 19,119-19,128, 1996.

König-Langlo, G., J. King, and P. Pettre, Climatology of the three coastal Antarctic stations Dumont d'Urville, Neumayer, and Halley, J. Geophys. Res., this issue.

Kottmeier, C., and B. Fay, Trajectories in the Antarctic lower troposphere, J. Geophys. Res., this issue.

Legrand, M., Chemistry of Antarctic snow and ice, J. Phys., 48, C1/77$\mathrm{Cl} / 86,1987$.

Legrand, M., F. Ducroz, D. Wagenbach, R. Mulvaney, and J. Hall, Ammonium in coastal Antarctic aerosol and snow: Role of the polar ocean and penguin emissions, J. Geophys. Res., this issue.

Limbert, D. W. S., The snow accumulation budget at Halley Bay in 1959 , and associated meteorological factors, BAS Bull., 2, 73-92, 1963.

McDonald, R. L., C. K. Unni, and R. A. Duce, Estimation of atmospheric sea-salt dry deposition: Wind speed and particle size dependence, $J$. Geophys. Res., 87, 1246-1250, 1982.

Minikin, A., D. Wagenbach, W. Graf, and J. Kipfstuhl, Spatial and seasonal variations of the snow chemistry at the central Filchner-Ronne Ice Shelf, Antarctica, Ann. Glaciol., 20, 283-290, 1994.

Minikin, A., M. Legrand, J. S. Hall, D. Wagenbach, C. Kleefeld, E. W. Wolff, E. C. Pasteur, and F. Ducroz, Sulfur-containing species (sulfate and MSA) in coastal Antarctic aerosol and precipitation, J. Geophys. Res., this issue.
Mulvaney, R., E. C. Pasteur, D. A. Peel, E. S. Saltzman, and P.-Y. Whung, The ratio of MSA to non-sea-salt sulphate in Antarctic Peninsula ice cores, Tellus, Ser. B, 44, 295-303, 1992.

Pasteur, E. C., Biogenic sulphur in Antarctic ice cores, Ph.D. thesis, Univ. of East Anglia, Norwich, England, 1996.

Pomeroy, J. W., and H. G. Jones, Wind-blown snow: sublimation, transport and changes to polar snow, in Chemical Exchange Between the Atmosphere and Polar Snow, NATO ASI Ser. I, vol. 43, edited by E. W. Wolff and R. C. Bales, pp. 453-489, Springer-Verlag, New York, 1996.

Pourchet, M., F. Pinglot, and C. Lorius, Some meteorological applications of radioactive fallout measurements in Antarctic snows, J. Geophys. Res., $88,6013-6020,1983$.

Pruppacher, H. R., and J. D. Klett, Microphysics of Clouds and Precipitation, D. Reidel, Norwell, Mass., 1978.

Shaw, G. E., Considerations on the origin and properties of the Antarctic aerosol, Rev. Geophys., 17, 1983-1998, 1979.

Steffensen, J. P., H. B. Clausen, and J. M. Christensen, On the spatial variability of impurity content and stable isotopic composition in recent Summit snow, in Chemical Exchange Between the Atmosphere and Polar Snow, NATO ASI Ser. I, vol. 43, edited by E. W. Wolff and R. C. Bales, pp. 607-615, Springer-Verlag, New York, 1996.

Waddington, E. D., J. Cunningham, and S. Harder, The effects of snow ventilation on chemical concentrations, in Chemical Exchange Between the Atmosphere and Polar Snow, NATO ASI Ser. I, vol. 43, edited by E. W. Wolff and R. C. Bales, pp. 403-451, Springer-Verlag, New York, 1996.

Wagenbach, D., W. Graf, A. Minikin, U. Trefzer, J. Kipfstuhl, H. Oerter, and N. Blindow, Reconnaissance of chemical and isotopic firm properties on top of Berkner Island, Antarctica, Ann. Glaciol., 20, 307-312, 1994.

Wagenbach, D., F. Ducroz, R. Mulvaney, L. Keck, A. Minikin, M. Legrand, J. S. Hall, and E. W. Wolff, Sea-salt aerosol in coastal Antarctic regions, J. Geophys. Res., this issue.

Wolff, E. W., Location, movement and reactions of impurities in polar ice, in Chemical Exchange Between the Atmosphere and Polar Snow, NATO ASI Ser. I, vol. 43, edited by E. W. Wolff and R. C. Bales, pp. 541-560, Springer-Verlag, New York, 1996.

Wolff, E. W., and R. C. Bales (Eds.), Chemical Exchange Between the Atmosphere and Polar Snow, NATO ASI Ser. I, vol. 43, Springer-Verlag, New York, 1996.

Wolff, E. W., M. Legrand, and D. Wagenbach, Coastal Antarctic aerosol and snowfall chemistry, J. Geophys. Res., this issue.

J. S. Hall, R. Mulvaney, E. C. Pasteur, and E. W. Wolff, British Antarctic Survey, Natural Environment Research Council, High Cross, Madingley Road, Cambridge CB3 OET, England. (e-mail: e.wolff@bas.ac.uk)

M. Legrand, Laboratoire de Glaciologie et Geophysique de l'Environnement, B. P. 96, 38402 St. Martin d'Hères Cedex, France. (email: Legrand@glaciog.ujf-grenoble.fr)

D. Wagenbach, Institut fur Umweltphysik, University of Heidelberg, D69120 Heidelberg, Germany. (e-mail: wa@uphys1.uphys.uni-heidelberg.de)

(Received March 20, 1997; revised September 3, 1997; accepted September 5, 1997.) 